\title{
FLORÍSTICA E ESTRUTURA DO ESTRATO ARBUSTIVO-ARBÓREO DE UMA FLORESTA RESTAURADA COM 40 ANOS, VIÇOSA, MG ${ }^{1}$
}

Aurino Miranda Neto ${ }^{2}$, Sebastião Venâncio Martins ${ }^{3}$, Kelly de Almeida Silva² e José Marinaldo Gleriani ${ }^{4}$

\begin{abstract}
RESUMO - Este estudo teve como objetivo avaliar o estrato arbustivo-arbóreo de uma floresta restaurada por meio de plantio, após 40 anos de sua implantação, no Município de Viçosa, MG. Foram alocadas na área total de 1 ha 16 parcelas contíguas de 25 x 25 m para avaliação do estrato arbustivo-arbóreo, registrando todos os indivíduos com CAP $\geq 15 \mathrm{~cm}$. Também se realizou a classificação quanto à classe sucessional e à síndrome de dispersão, bem como a análise física e química do solo da floresta restaurada. Registraram-se 1.432 indivíduos, 112 espécies e 36 famílias, sendo 95 espécies nativas e 16 exóticas, com maior VI para espécie Guarea guidonia e família Fabaceae, alta diversidade $\left(\mathrm{H}^{\prime}=3,51\right)$ e baixa dominância ecológica $\left(\mathrm{J}^{\prime}=0,743\right)$, maior porcentagem da classe sucessional secundária inicial, em nível de espécie $(34,82 \%)$, e de secundária tardia, em nível de indivíduos (34,29\%), e predomínio de síndrome de dispersão zoocórica. A área basal foi de $47,8 \mathrm{~m}$ /ha e a altura média de $10,6 \mathrm{~m}$, variando de $2,2 \mathrm{~m}$ a 27,2 $\mathrm{m}$. A camada de $0-20 \mathrm{~cm}$ do solo apresentou média saturação de bases ( $\mathrm{V}=43,40 \%)$ e a camada de $20-40 \mathrm{~cm}$ baixa saturação de bases $(\mathrm{V}=34,70 \%)$, com densidades do solo $\left(1,08 \mathrm{e} 1,07 \mathrm{~kg} / \mathrm{m}^{3}\right)$ dentro da faixa ideal para solos com textura argilosa. A floresta restaurada, após 40 anos, alcançou patamar semelhante às Florestas Estacionais Semideciduais, em estádio avançado de sucessão, da região de Viçosa, MG, em termos dos parâmetros fitossociológicos no estrato arbustivo-arbóreo.
\end{abstract}

Palavras-chave: Fitossociologia, Restauração Florestal e Indicadores de restauração.

\section{FLORISTIC AND STRUCTURE OF THE SHRUB-TREE LAYER OF A FOREST RESTORED TO 40 YEARS, VIÇOSA, MG}

\begin{abstract}
The objective of this study was to evaluate the woody shrub layer of a restored forest through planting after 40 years of its implementation, in Viçosa, MG. It was allocated in the total area of one hectare, 16 contiguous plots of $25 \times 25 \mathrm{~m}$ to assess the woody shrub layer, recording all individuals with $P B H \geq 15$ cm.It was recorded 1,432 individuals, 112 species and 36 families, of which 95 were native and 16 were exotic species, with higher Importance Value for Guarea guidonia and Fabaceae family, high diversity $\left(H^{\prime}=\right.$ $3.51)$ and low ecological dominance $\left(J^{\prime}=0.743\right)$, higher percentage of early secondary successional class at the species level (34.82\%), and late secondary at the level of individuals (34.29\%), and predominance of syndrome of seed dispersal by animals. The basal area was $47.8 \mathrm{~m}^{2} / \mathrm{ha}$ and the average height of 10.6 $m$, ranging from $2.2 \mathrm{~m}$ to $27.2 \mathrm{~m}$. The $0-20 \mathrm{~cm}$ layer soil had a an average base saturation $(V=43.40 \%)$ and $20-40 \mathrm{~cm}$ layer of low base saturation $(\mathrm{V}=34.70 \%)$, with soil density $\left(1.08\right.$ and $\left.1.07 \mathrm{~kg} / \mathrm{m}^{3}\right)$ within the ideal range for clay soils. The restored forest after 40 years reached a level similar to semideciduous seasonal forests in advanced stages of succession, in Viçosa, MG, in terms of phytosociological parameters.
\end{abstract}

Keywords: Phytosociology, Forest Restoration and Restoration indicators.

\footnotetext{
${ }^{1}$ Recebido em 23.11.2011 aceito para publicação em 04.06.2012.

${ }^{2}$ Programa de Pós-Graduação em Ciência Florestal pela Universidade Federal de Viçosa, Departamento de Engenharia Florestal, Brasil.E-mail:<aur.neto@gmail.com>e<kellyalmeidaenf@yahoo.com.br>.

${ }^{3}$ LARF - Laboratório de Restauração Florestal, Departamento de Engenharia Florestal da Universidade Federal de Viçosa, Viçosa, MG, Brasil.E-mail: <venancio@ufv.br>.

${ }^{4}$ Departamento de Engenharia Florestal da Universidade Federal de Viçosa, Viçosa, MG, Brasil. E-mail: <gleriani@ufv.br>.
} 


\section{INTRODUÇÃO}

A Zona da Mata está inserida no bioma Mata Atlântica, composto em quase sua totalidade pela Floresta Estacional Semidecidual e detentor de extraordinária diversidade e numerosas espécies endêmicas, apesar da drástica redução de sua cobertura florestal ao longo dos séculos após o descobrimento do Brasil (DEAN, 1996; SERVIÇO FLORESTAL BRASILEIRO, 2009).

A Floresta Estacional Semidecidual está condicionada em duas estacionalidades climáticas, uma com seca fisiológica, provocada pelo intenso frio do inverno, e outra marcada por intensas chuvas de verão (VELOSO, 1991). Apresenta dossel irregular, com árvores de até $30 \mathrm{~m}$, troncos com cascas grossas sustentando ramos robustos, copas amplas, ralas e esgalhadas (VELOSO, 1992).

Diante da alta fragmentação em que se encontra atualmente a Floresta Estacional Semidecidual, a restauração florestal possui importante papel na conservação da biodiversidade dessa fitofisionomia, buscando estabelecer populações representativas da flora nativa regional e diversidade genética.

A avaliação da restauração florestal é baseada na análise da semelhança entre a área restaurada e outras áreas de referência, dentro do mesmo ecossistema, comparando a estrutura, função, composição e as relações dos processos ecológicos (HOBBS; NORTON, 1996). Portanto, ao avaliar uma floresta restaurada, utilizam-se estudos fitossociológicos.

Estudos fitossociológicos podem ser realizados para diversas finalidades: avaliação de impacto ambiental, auxílio na fitogeografia, exploração florestal sustentável, conservação e restauração de ecossistemas, avanço do conhecimento científico, entre outros (DURIGAN, 2009). É importante que todo estudo sobre comunidade vegetal tenha propósito claro.

A análise da florística e estrutura do estrato arbustivo-arbóreo de ecossistemas restaurados ou em processos de restauração possibilita alavancar os conhecimentos ecológicos desses ecossistemas e avaliar se o projeto de restauração está superando as fases de sucessões ou, também, se necessita de intervenções para, finalmente, chegar a um estado mais próximo possível de uma floresta em equilíbrio e, ainda, subsidiar avanços em pesquisas posteriores.
Portanto, objetivou-se neste estudo avaliar o estrato arbustivo-arbóreo de uma floresta restaurada por meio de plantio, após 40 anos de sua implantação, no Município de Viçosa, MG, bem como analisar o solo, a caracterização da síndrome de dispersão e a classe sucessional.

\section{MATERIAL E MÉTODOS}

\section{1. Área de estudo}

O estudo foi realizado em uma floresta restaurada por meio de plantio utilizando espécies nativas e exóticas com idade de 40 anos após sua implantação, que faz parte da "Mata da Silvicultura", pertencente ao Departamento de Engenharia Florestal, localizado no Campus da Universidade Federal de Viçosa (UFV), no Município de Viçosa (2045' 14"S e 4245'53"W), na região da Zona da Mata de Minas Gerais. A pesquisa foi realizada em uma área de estudo de 1 ha (25 x 400 m).

O clima na região é do tipo Cwb (Köppen), mesotérmico com verões quentes e chuvosos e invernos frios e secos, com temperatura média anual de 21,8 ${ }^{\circ} \mathrm{C}$ e precipitação pluviométrica média anual de $1.314,2$ mm (CASTRO et al., 1983). A região apresenta altitudes entre 670 e $730 \mathrm{~m}$ e relevo acidentado, variando de fortemente ondulado a montanhoso (MARISCALFLORES, 1993).

A vegetação da área de estudo era resultante de plantio heterogêneo de espécies nativas e exóticas no espaçamento de 4,0 x 5,0 m, perfazendo um total de 485 indivíduos e 56 espécies. O plantio foi realizado entre os anos de 1967 e 1969 , pelo setor de Dendrologia da Universidade Federal de Viçosa. Anteriormente à restauração havia no local plantio de eucalipto, caracterizando a área com histórico de perturbação.

\subsection{Procedimentos de campo}

Foram alocadas nessa área total de 1 ha 16 parcelas contíguas de 25 x $25 \mathrm{~m}$, para avaliação dos indivíduos plantados e indivíduos pertencentes ao estrato arbustivoarbóreo. Os indivíduos mortos em pé também foram amostrados.

Foram reconhecidas e medidas a circunferência e altura de todos os indivíduos arbustivo-arbóreos com circunferência a $1,30 \mathrm{~m}$ de altura, igual ou superior a $15 \mathrm{~cm}$. Das espécies não reconhecidas em campo, coletou-se material botânico para posterior comparação 
com o material depositado no Herbário VIC da Universidade Federal de Viçosa, mediante consulta a especialistas e na literatura. As espécies foram classificadas em famílias e tiveram os nomes científicos e respectivos autores atualizados pela base de dados do Missouri Botanical Garden, através do site www.tropicos.org, de acordo com o sistema do Angiosperm Phylogeny Group III (APG III, 2009).

As espécies amostradas foram classificadas em categorias sucessionais, de acordo com o proposto por Gandolfi et al. (1995), sendo: pioneira, secundária inicial, secundária tardia e não classificada. Para auxiliar nessa classificação, foi realizado levantamento na literatura sobre a classificação adotada por diferentes autores. Quando surgiram dúvidas, a espécie foi denominada não classificada. As espécies também foram classificadas, quanto às síndromes de dispersão de propágulos, em zoocóricas, anemocóricas e autocóricas (PIJL, 1982), com base na literatura especializada.

\subsection{Análise de dados}

Foram calculados os parâmetros fitossociológicos clássicos (Densidade, Frequência, Dominância, Valor de Importância), descritos por Mueller-Dombois e Ellenberg (1974); o índice de diversidade de ShannonWiener (H') (MAGURRAN, 1988); e a equabilidade (J') (PIELOU, 1975), através do programa FITOPAC 2.1 (SHEPHERD, 2010).

Calcularam-se o somatório e a porcentagem de indivíduos e de espécies das categorias sucessionais e síndromes de dispersão. As médias percentuais calculadas nas classes sucessionais e síndromes de dispersão, em nível de indivíduos e de espécies por parcela, foram comparadas pela Análise de Variância (ANOVA), utilizando-se o teste F, e posteriormente aplicou-se o teste de Tukey a 5\% de significância. As análises estatísticas foram realizadas por meio do programa STATISTICA 7.0 (STATSOFT, 2004).

\subsection{Análise do solo}

Realizou-se uma análise físico-química do solo da floresta restaurada. Foram retiradas duas amostras simples de solo (0-20 cm e $20-40 \mathrm{~cm}$ de profundidade) no centro de cada parcela de $25 \times 25 \mathrm{~m}$. As amostras foram misturadas, obtendo-se, assim, duas amostras compostas (representando as duas profundidades). Em seguida, foi retirada uma porção de aproximadamente $0,5 \mathrm{~kg}$ de cada amostra composta e enviada para análise no Laboratório de Análises de Solos da UFV.

\section{RESULTADOS}

Foram registrados em 1 ha 1.432 indivíduos, pertencentes a 112 espécies, 98 gêneros e 36 famílias botânicas. Desses, havia 19 indivíduos mortos em pé. Em relação aos indivíduos do plantio, restaram 178 vivos, dos 485 plantados no trecho de 1 ha restaurado.

As espécies exclusivas do plantio, ou seja, que não se propagaram na floresta restaurada, representaram $16,96 \%$ do total de espécies amostradas na área, distribuídas, quanto à sua origem, em 13 nativas e seis exóticas. Já as espécies exclusivas do estrato arbustivoarbóreo não plantado, ou seja, espécies estabelecidas na floresta restaurada provenientes do entorno, representaram 49,10\% do total de espécies, distribuídas em 53 nativas e duas exóticas. As espécies comuns ao grupo das plantadas e pertencentes ao estrato arbustivo-arbóreo não plantado perfazem 29 nativas, oito exóticas e uma sem classificação. A espécie não classificada quanto à sua origem recebeu essa denominação pelo fato de seu reconhecimento ter alcançado apenas o nível de família.

Na distribuição das espécies amostradas por classe sucessional, verificou-se que houve variação significativa, com maior proporção de secundárias iniciais, tanto no plantio $(35,09 \%)$ quanto no estrato arbustivo-arbóreo não plantado (36,56\%), bem como quando se analisou a área total $(34,82 \%)$ (Figura 1). Em nível de indivíduos, a maior proporção entre as espécies do plantio foi alcançada pela classe secundária inicial $(41,24 \%)$, enquanto no estrato arbustivo-arbóreo não pertencente ao plantio e na área total a classe secundária tardia obteve maiores proporções, com $36,33 \%$ e $34,29 \%$, respectivamente (Figura 1).

Para a síndrome de dispersão, a proporção de espécies e indivíduos da classe zoocoria foi significativamente maior em relação às demais síndromes de dispersão entre as espécies do plantio $(40,35 \%$ de espécies e 41,24\% de indivíduos), estrato arbustivoarbóreo não plantado $(52,69 \%$ de espécies e $57,12 \%$ de indivíduos) e em área total $(51,79 \%$ de espécies e $55,73 \%$ de indivíduos) (Figura 2).

Revista Árvore, Viçosa-MG, v.36, n.5, p.869-878, 2012 
Tabela 1 - Parâmetros fitossociológicos das principais espécies amostradas no estrato arbustivo-arbóreo de uma floresta restaurada com 40 anos, Viçosa, MG. NI = número de indivíduos; DR = densidade relativa; FR = frequência relativa; DoR = dominância realtiva; VC = valor de cobertura; e VI = valor de importância.

Table 1 - Phytosociological parameters for the main species sampled in the tree and shrub layer of a forest restored with 40 years of age in Viçosa, MG. NI = number of individuals; $D R=$ relative density; $R F=$ relative frequency; DoR $=$ relative dominance; $V C=$ coverage value; and $V I=$ importance value.

\begin{tabular}{|c|c|c|c|c|c|c|}
\hline Espécies & NI & DR & FR & DoR & VC & VI \\
\hline Guarea guidonia (L.) Sleumer & 307 & 21,44 & 3,92 & 6,69 & 28,13 & 32,05 \\
\hline Archontophoenix cunninghamiana $\mathrm{H}$. Wendl. e Drude & 128 & 8,94 & 1,96 & 3,25 & 12,18 & 14,15 \\
\hline Piptadenia gonoacantha (Mart.) J.F. Macbr. & 67 & 4,68 & 3,92 & 4,1 & 8,78 & 12,7 \\
\hline Luehea grandiflora Mart. & 72 & 5,03 & 3,64 & 3,01 & 8,04 & 11,68 \\
\hline Spathodea campanulata P. Beauv. & 52 & 3,63 & 2,52 & 5,11 & 8,74 & 11,26 \\
\hline Centrolobium robustum (Vell.) Mart. ex Benth. & 94 & 6,56 & 0,84 & 3,14 & 9,7 & 10,54 \\
\hline Anadenanthera peregrina (L.) Speg. & 33 & 2,3 & 2,52 & 3,09 & 5,4 & 7,92 \\
\hline Syagrus romanzoffiana (Cham.) Glassman & 37 & 2,58 & 2,24 & 2,85 & 5,43 & 7,68 \\
\hline Caesalpinia peltophoroides Benth. & 23 & 1,61 & 1,68 & 4,01 & 5,61 & 7,29 \\
\hline Cecropia glaziovi Snethl. & 25 & 1,75 & 3,36 & 2,03 & 3,78 & 7,14 \\
\hline Zeyheria tuberculosa (Vell.) Bureau & 33 & 2,3 & 3,08 & 1,51 & 3,81 & 6,9 \\
\hline Senna multijuga (Rich.) H.S. Irwin e Barneby & 23 & 1,61 & 2,52 & 2,08 & 3,69 & 6,21 \\
\hline Morta & 19 & 1,33 & 3,08 & 1,67 & 3 & 6,08 \\
\hline Pterocarpus violaceus Vogel & 13 & 0,91 & 0,84 & 4,26 & 5,17 & 6,01 \\
\hline Miconia cinnamomifolia (DC.) Naudin & 14 & 0,98 & 2,52 & 2,14 & 3,12 & 5,64 \\
\hline Ficus microcarpa L. f. & 2 & 0,14 & 0,28 & 5,12 & 5,26 & 5,54 \\
\hline Caryota urens L. & 33 & 2,3 & 0,84 & 2,06 & 4,36 & 5,2 \\
\hline Nectandra oppositifolia Nees e Mart. & 25 & 1,75 & 3,08 & 0,27 & 2,02 & 5,1 \\
\hline Rhus succedanea L. & 25 & 1,75 & 2,8 & 0,47 & 2,22 & 5,02 \\
\hline Pseudopiptadenia contorta (DC.) G.P. Lewis e M.P. Lima & 6 & 0,42 & 0,56 & 3,98 & 4,4 & 4,96 \\
\hline Sterculia chicha A. St.-Hil. ex Turpin & 10 & 0,7 & 0,84 & 2,52 & 3,22 & 4,06 \\
\hline Cassia ferruginea (SCHRADER) Schrader ex DC. & 13 & 0,91 & 1,4 & 1,75 & 2,65 & 4,05 \\
\hline Vernonia diffusa Less. & 16 & 1,12 & 2,52 & 0,25 & 1,36 & 3,89 \\
\hline Pachira aquatica Aubl. & 28 & 1,96 & 1,12 & 0,64 & 2,59 & 3,71 \\
\hline Trichilia lepidota Mart. & 18 & 1,26 & 2,24 & 0,2 & 1,46 & 3,7 \\
\hline Nectandra lanceolata Nees & 15 & 1,05 & 1,96 & 0,16 & 1,2 & 3,16 \\
\hline Genipa americana $\mathrm{L}$. & 14 & 0,98 & 1,12 & 0,88 & 1,86 & 2,98 \\
\hline Senna macranthera (DC. ex Collad.) H.S. Irwin e Barneby & 10 & 0,7 & 1,96 & 0,3 & 0,99 & 2,95 \\
\hline Lonchocarpus muehlbergianus Hassl. & 19 & 1,33 & 0,84 & 0,78 & 2,11 & 2,95 \\
\hline Myracrodruon urundeuva Allemão & 11 & 0,77 & 1,12 & 1,02 & 1,79 & 2,91 \\
\hline Joannesia princeps Vell. & 4 & 0,28 & 0,28 & 2,33 & 2,6 & 2,88 \\
\hline Rollinia sylvatica (A. St.-Hil.) Martius & 9 & 0,63 & 1,68 & 0,51 & 1,14 & 2,82 \\
\hline Pterogyne nitens Tul. & 6 & 0,42 & 0,56 & 1,7 & 2,12 & 2,68 \\
\hline Gmelina arborea Roxb. ex Sm. & 2 & 0,14 & 0,28 & 2,18 & 2,32 & 2,6 \\
\hline Casuarina equisetifolia $\mathrm{L}$. & 6 & 0,42 & 0,56 & 1,5 & 1,92 & 2,48 \\
\hline Caesalpinia echinata Lam. & 5 & 0,35 & 0,28 & 1,83 & 2,18 & 2,46 \\
\hline Siparuna guianensis Aubl. & 12 & 0,84 & 1,4 & 0,07 & 0,91 & 2,31 \\
\hline Paratecoma peroba (Record e Mell) Kuhlm. & 3 & 0,21 & 0,28 & 1,77 & 1,98 & 2,26 \\
\hline Guatteria nigrescens Mart. & 7 & 0,49 & 1,4 & 0,31 & 0,8 & 2,2 \\
\hline Acacia polyphylla DC. & 10 & 0,7 & 1,4 & 0,1 & 0,8 & 2,2 \\
\hline Lecythis pisonis Cambess. & 2 & 0,14 & 0,28 & 1,66 & 1,8 & 2,08 \\
\hline Cariniana estrellensis (Raddi) Kuntze & 5 & 0,35 & 1,12 & 0,6 & 0,95 & 2,07 \\
\hline Myrcia fallax (Rich.) DC. & 8 & 0,56 & 1,4 & 0,05 & 0,61 & 2,01 \\
\hline
\end{tabular}

Revista Árvore, Viçosa-MG, v.36, n.5, p.869-878, 2012 
O índice de diversidade de Shannon-Wiener (H') foi de 3,51 e o índice de equabilidade (J'), de 0,743. Obtiveram-se $47,8 \mathrm{~m}^{2}$ por hectare de área basal.

Guarea guidonia (L.) Sleumer destacou-se expressivamente em relação às demais espécies, representando $21,43 \%$ dos indivíduos amostrados e $10,70 \%$ do valor de importância (VI). Em relação às famílias, o destaque foi para Fabaceae, Meliaceae, Arecaceae, Malvaceae e Bignoniaceae, perfazendo $59,33 \%$ do VI total e $40,08 \%$ dos indivíduos amostrados.
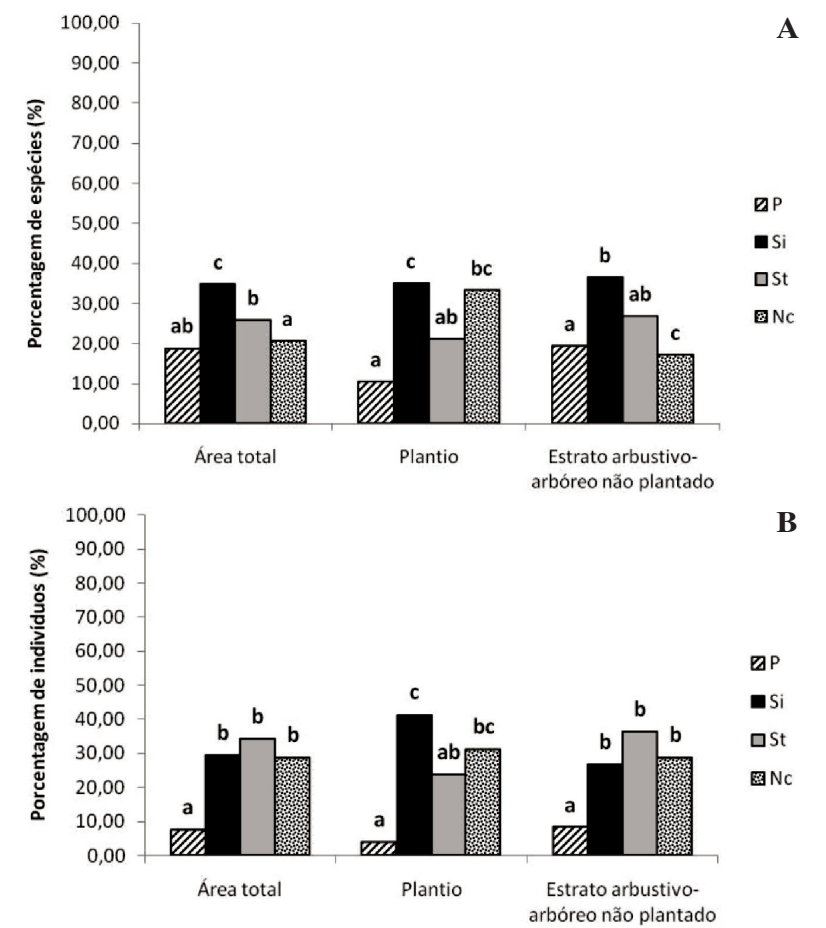

Figura 1 - Distribuição, por classe sucessional, em nível de espécies (A) e indivíduos (B), amostrados na floresta restaurada com 40 anos, em Viçosa, MG P = pioneira; $\mathrm{Si}$ = secundária inicial; $\mathrm{St}$ = secundária tardia; $\mathrm{e}$ $\mathrm{Nc}=$ não classificada. Valores seguidos de mesma letra dentro de cada grupo não diferem significativamente entre si, pelo teste de Tukey $(p>0,05)$

Figure 1 - Distribution by successional class, species-level (A) and individuals-level (B), sampled in the restored forest at 40 years of age in Viçosa, $M G$. $P=$ pioneer, $S i=$ early secondary; $S t=$ late secondary; $N c=$ not classified. Values followed by same letter within each group did not differ significantly by Tukey test $(p>0.05)$.
A estrutura vertical da área de estudo possuía altura média de $10,6 \mathrm{~m}$, variando de $2,2 \mathrm{~m}$ a 27,2 $\mathrm{m}$. Entre as espécies de maior VI, destacou-se Anadenanthera peregrina, com altura máxima de $27,2 \mathrm{~m}$, seguida de Piptadenia gonoacantha e Cecropia glaziovi, ambas com altura máxima de 24,2 m, Caesalpinia peltophoroides $(23,2 \mathrm{~m})$ e Centrolobium robustum $(22,6 \mathrm{~m})$.

Com relação à variável diâmetro médio, entre as espécies de maior VI, destacaram-se Ficus microcarpa $(126,06 \mathrm{~cm})$, Pseudopiptadenia contorta
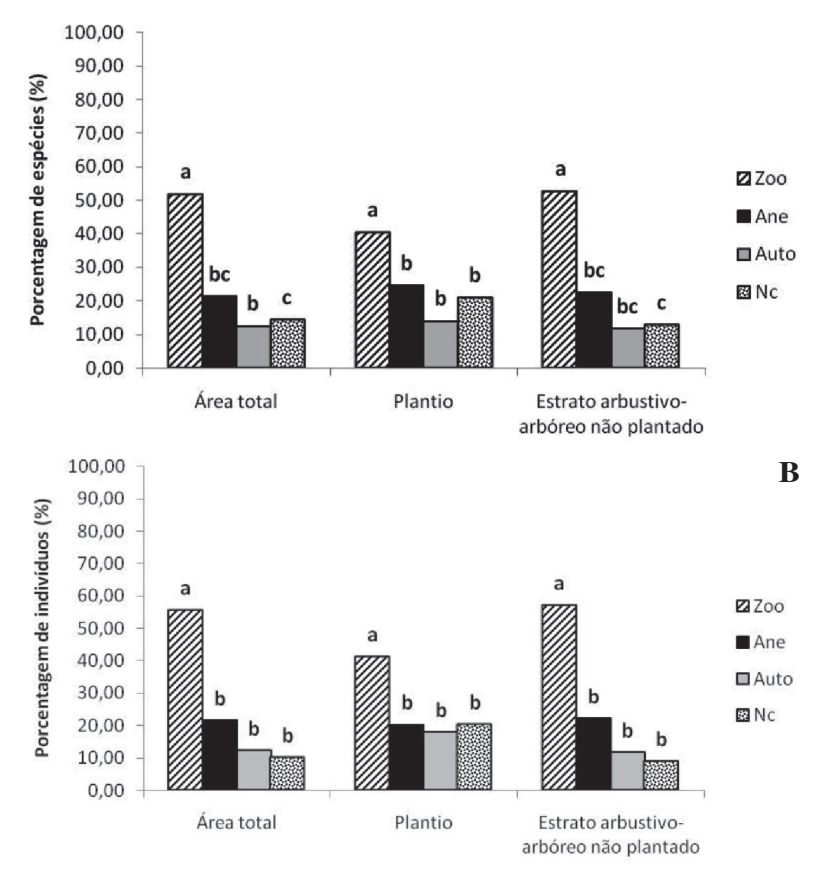

Figura 2 - Distribuição, por síndrome de dispersão, em nível de espécies (A) e indivíduos (B) amostrados na floresta restaurada com 40 anos, em Viçosa, MG. Zoo = zoocoria; Ane $=$ anemocoria; Auto = autocoria; e Nc = não classificada. Valores seguidos de mesma letra dentro de cada grupo não diferem significativamente entre si, pelo teste de Tukey $(p>0,05)$.

Figure 2 -Distribution by dispersion syndrome at specieslevel (A) and individual-level (B), sampled in the restored forest at 40 years of age in Viçosa, $M G$. Zoo = zoochory; Ane = anemochory; Auto = autocory; $N c=$ not classified . Values followed by the same letter within each group did not differ significantly by Tukey test $(p>0.05)$.

Revista Árvore, Viçosa-MG, v.36, n.5, p.869-878, 2012 
(48,46 cm), Pterocarpus violaceus $(33,98 \mathrm{~cm})$, Luehea grandiflora $(26,94 \mathrm{~cm})$ e Miconia cinnamomifolia $(23,50 \mathrm{~cm})$.

A camada de 0-20 cm do solo apresentou valores superiores em relação à camada de $20-40 \mathrm{~cm}$ para as variáveis acidez ativa do solo, P, K, Ca trocável, Mg trocável, CTC efetiva, CTC pH7, saturação de bases, matéria orgânica e fósforo remanescente, bem como valores inferiores das variáveis acidez trocável, acidez potencial e saturação de alumínio (Tabela 2).

O resultado da análise granulométrica do solo da floresta restaurada incluiu o solo da camada de 0-20 cm na classe textural argila, apresentando valores mais elevados para argila e mais baixos para areia (grossa e fina) em relação ao solo da camada de 20$40 \mathrm{~cm}$, incluído na classe textural muito argilosa. Quanto aos valores de densidade, o perfil de 0-20 cm apresentou mínima diferença em relação ao perfil de $20-40 \mathrm{~cm}$, com valores de $1,08 \mathrm{~kg} / \mathrm{cm}^{3}$ e $1,07 \mathrm{~kg} / \mathrm{cm}^{3}$, respectivamente.

Tabela 2 - Resultados da análise química das amostras de solo coletadas na floresta restaurada com 40 anos, em Viçosa, MG.

Table 2 - esults of chemical analysis for soil samples collected in the forest restored at 40 years of age in Viçosa, MG.

\begin{tabular}{|c|c|c|}
\hline \multirow{2}{*}{ Parâmetros } & \multicolumn{2}{|c|}{ Amostra } \\
\hline & $0-20 \mathrm{~cm}$ & $20-40 \mathrm{~cm}$ \\
\hline $\mathrm{pH} \mathrm{H} 20$ & 5,22 & 5,13 \\
\hline $\mathrm{P}\left(\mathrm{mg} / \mathrm{dm}^{3}\right)$ & 4,80 & 2,20 \\
\hline $\mathrm{K}\left(\mathrm{mg} / \mathrm{dm}^{3}\right)$ & 80,00 & 52,00 \\
\hline $\mathrm{Ca} 2+(\mathrm{cmolc} / \mathrm{dm} 3)$ & 3,54 & 2,44 \\
\hline $\operatorname{Mg}^{2}\left(\mathrm{cmolc} \mathrm{dm}^{3}\right)$ & 1,48 & 1,09 \\
\hline $\mathrm{Al}^{3}\left(\mathrm{cmolc} / \mathrm{dm}^{3}\right)$ & 0,20 & 0,40 \\
\hline $\mathrm{H}+\mathrm{Al}\left(\mathrm{cmolc} / \mathrm{dm}^{3}\right)$ & 6,80 & 6,90 \\
\hline $\mathrm{SB}\left(\mathrm{cmolc} / \mathrm{dm}^{3}\right)$ & 5,22 & 3,66 \\
\hline (t) $\left(\mathrm{cmolc} / \mathrm{dm}^{3}\right)$ & 5,42 & 4,06 \\
\hline $\mathrm{T}\left(\mathrm{cmolc} / \mathrm{dm}^{3}\right)$ & 12,02 & 10,56 \\
\hline $\mathrm{V}(\%)$ & 43,40 & 34,70 \\
\hline $\mathrm{m}(\%)$ & 3,70 & 9,90 \\
\hline MO (dag/kg) & 5,61 & 4,43 \\
\hline P-rem (mg/L) & 26,00 & 19,90 \\
\hline
\end{tabular}

pH em água - relação 1:2,5; $\mathrm{P}-\mathrm{K}$ - Extrator Mehlich 1; Ca - MG - Al - Extrator: $\mathrm{KCl}-1 \mathrm{~mol} / \mathrm{L} ; \mathrm{H}+\mathrm{Al}$ - Extrator Acetato de Cálcio $0,5 \mathrm{~mol} / \mathrm{L}$ - pH 7,0; SB = Soma de Bases Trocáveis; $(\mathrm{t})$ - Capacidade de Troca Catiônica Efetiva; $(\mathrm{T})$ - Capacidade de Troca Catiônica a pH 7,0; V = Índice de Saturação de Bases; $m$ = Índice de Saturação de Alumínio; MO = Matéria Orgânica - C. Org x 1,724 - WalkleyBlack; e P-rem = Fósforo remanescente.

Revista Árvore, Viçosa-MG, v.36, n.5, p.869-878, 2012

\section{DISCUSSÃO}

A riqueza de espécies (112) amostradas na área de estudo se enquadra nos levantamentos realizados em Floresta Estacional Semidecidual na região de Viçosa, MG, com variação entre 91 e 197 espécies (VOLPATO, 1994; SILVA et al., 2000; SENRA, 2000; PAULA et al., 2004; MARANGON, 1999; LOPES et al., 2002; MEIRANETO; MARTINS, 2002; MARANGON etal., 2003; SILVA et al., 2003; SILVA et al., 2004; CAMPOS et al., 2006; FERREIRA JÚNIOR et al., 2007).

A densidade de indivíduos por hectare (1.432) amostrada foi superior à encontrada por Silva et al. (2003), com 632 indivíduos.ha-1, e Silva et al. (2004), com 1.275 indivíduos.ha ${ }^{-1}$, e inferior à obtida por Paula et al. (2004) (1.826 indivíduos.ha-1) e Campos et al. (2006) (1.704 indivíduos.ha ${ }^{-1}$ ), todos em Floresta Estacional Semidecidual na região de Viçosa, $M G$.

Em relação à riqueza de espécies e densidade de indivíduos, os valores indicaram semelhanças com áreas de Floresta Estacional Semidecidual na mesma região, sendo um dos indicativos de que a restauração obteve êxito.

Comparando com áreas restauradas, a densidade foi superior à encontrada por Castanho (2009) em áreas restauradas com espécies exóticas e nativas em Iracemápolis, Estado de São Paulo, com 18 anos (1.318 indivíduos.ha-1 ${ }^{-1}$ e 20 anos (1.214 indivíduos.ha-1), e inferior à encontrada por Souza e Batista (2004) em áreas restauradas com espécies nativas, no Oeste do Estado de São Paulo, com cinco anos (2.078 indivíduos.ha ${ }^{-1}$ ), com nove anos (2.744 indivíduos. ha-1) e com 10 anos (2.247 indivíduos.ha-1).

A densidade de indivíduos pertencentes ao plantio diminuiu 63,3\% em relação à densidade inicial quando do plantio das mudas, equivalendo à diferença de densidade encontrada por Castanho (2009) em uma área com 20 anos de restauração por plantio $(65,2 \%)$. Isso indica grande mortalidade dos indivíduos plantados, em que, possivelmente, não foram todos os indivíduos que conseguiram se adaptar, uma vez que foram utilizadas espécies de diversos grupos ecológicos, ou não sobreviveram em virtude do tempo de vida das espécies.

Entre as espécies exóticas que se estabeleceram no estrato arbustivo-arbóreo não plantado, destacou-se Archontophoenix cunninghamiana, com 125 indivíduos 
amostrados. Archontophoenix cunninghamiana é uma palmeira originária da Austrália (WATERHOUSE; QUINN, 1978), amplamente utilizada em ornamentação de praças, jardins e arborização urbana, em que floresce durante todo o ano, sendo visitada por diversas abelhas e aves (PIRANI; CORTOPASSI-LAURINO, 1994; HASUI; HÖFLING, 1998), considerada uma espécie invasora, bastante agressiva. Archontophoenix cunninghamiana foi relatada invadindo áreas mais sombreadas de um fragmento florestal (10 ha) da Universidade de São Paulo, SP, não ocorrendo em áreas perturbadas mais abertas (DISLICH et al., 2002), tornando essa espécie ameaça às áreas de florestas mais conservadas.

Das 41 espécies nativas plantadas, $73,1 \%$ das espécies do plantio conseguiram se estabelecer na área. Acrescentando mais 53 espécies nativas amostradas exclusivamente no estrato arbustivoarbóreo não plantado, perfizeram-se um total de 83 espécies nativas. Notou-se a maior percentagem de espécies nativas oriundas de propágulos dos vários fragmentos de Floresta Estacional Semidecidual presentes próximos à área de estudo, especialmente a "Mata da Silvicultura", vizinha à floresta restaurada. A "Mata da Silvicultura" possui 17 ha (MEIRA NETO e MARTINS, 2002) e encontra-se protegida de corte e extração de madeira desde o ano de 1936 (MARISCALFLORES, 1993).

Na distribuição das espécies por classe sucessional, verificou-se, possivelmente, influência das espécies inicialmente plantadas, em sua maioria secundária inicial, na maior proporção da mesma classe no estrato arbustivoarbóreo não plantado, associadas ao sucesso de reprodução dessas espécies. Já na distribuição dos indivíduos por classe sucessional, entre indivíduos do plantio, permanece a maior densidade de secundárias iniciais, enquanto no estrato arbustivo-arbóreo não plantado prevalece a classe secundária tardia, mostrando que a floresta se encaminha para um estádio sucessional avançado, uma vez que a classificação por indivíduos reflete melhor a estrutura da comunidade e o seu estádio sucessional.

Na distribuição das espécies por síndrome de dispersão tanto para nível de espécie quanto para nível de indivíduo, a maior proporção foi da classe zoocoria, entre as plantadas e no estrato arbustivo-arbóreo não plantado, seguida distante pela classe anemocoria e pela classe autocoria. Piña-Rodrigues (1990) afirmou que, em estádios sucessionais mais avançados, a dispersão zoocórica possui função importante na manutenção, distribuição espacial e frequência das espécies.

O índice de diversidade de Shannon-Wiener (H') encontrado para a floresta restaurada $(3,51)$ indicou que a área possuía diversidade alta, e o índice de equabilidade (J') $(0,743)$ mostrou ser uma área floristicamente heterogênea, com baixa dominância ecológica.

Comparando com outros estudos em Floresta Estacional Semidecidual na mesma região deste estudo, verificou-se que a diversidade foi inferior ao obtido por Silva et al. (2004) ( $\left.\mathrm{H}^{\prime}=3,56\right)$, Marangon et al. (2007) $\left(H^{\prime}=4,25\right)$ e Campos et al. (2006) $\left(H^{\prime}=3,52\right)$, mas superior ao conseguido por Pinto Sobrinho et al. (2009) $\left(\mathrm{H}^{\prime}=3,41\right)$ e Pinto et al. (2007) $\left(\mathrm{H}^{\prime}=3,31\right)$.

Comparando com outros estudos em áreas restauradas por plantio, verificou-se que índice de diversidade foi superior ao das áreas estudadas por Souza e Batista (2004): área com cinco anos $\left(H^{\prime}=2,18\right)$, com nove anos $\left(\mathrm{H}^{\prime}=2,45\right)$ e com 10 anos $\left(\mathrm{H}^{\prime}=3,03\right)$; e por Castanho (2009): área com 18 anos $\left(H^{\prime}=3,47\right)$ e com 20 anos $\left(H^{\prime}=3,10\right)$.

Entre as famílias em destaque, com maiores VI, amostradas neste estudo, apenas Fabaceae foi encontrada em destaque em outros estudos realizados em fragmentos da região de Viçosa (VOLPATO, 1994; SENRA, 2000; LOPES et al., 2002; MEIRA NETO; MARTINS, 2002; SILVA JÚNIOR et al., 2004; MARANGON et al., 2003; CAMPOS et al., 2006; FERREIRA JÚNIOR et al., 2007), demonstrando certa dissimilaridade em relação a famílias, influência direta do plantio.

A área basal $\left(48,7 \mathrm{~m}^{2} . \mathrm{ha}^{-1}\right)$ deste estudo foi superior aos valores obtidos em fragmentos de Floresta Estacional Semidecidual da região de Viçosa, MG, por Pinto et al. (2007), que encontraram em floresta secundária inicial $18,4 \mathrm{~m}^{2} . \mathrm{ha}^{-1}$ de área basal e em floresta madura, com estádio sucessional avançado, $38,2 \mathrm{~m}^{2}$. ha $\mathrm{a}^{-1}$ de área basal. E por Campos et al. (2006), que encontraram uma área basal de $38,4 \mathrm{~m}^{2} \cdot \mathrm{ha}^{-1}$ em outro fragmento de floresta madura. Portanto, infere-se que a floresta restaurada, quando comparada com florestas da região, encontrava-se em estádio avançado de sucessão para o parâmetro área basal.

Revista Árvore, Viçosa-MG, v.36, n.5, p.869-878, 2012 
A altura média $(10,6 \mathrm{~m})$ foi superior à do estudo de Castanho (2009) para floresta restaurada com 18 anos $(9,23 \mathrm{~m})$ e inferior à área com 20 anos $(11,08)$. Todavia, essas áreas apresentaram limites entre sete e $17 \mathrm{~m}$ de altura, menor que a variação deste trabalho (2,2 a 27,2 m). Isso demonstra uma floresta com maior diversidade de estratos, ou seja, mais heterogênea, e com árvores de porte mais elevado.

A camada de 0-20 cm do solo apresentou acidez ativa do solo média; Ca trocável e Mg trocável com valores considerados bons; acidez trocável muito baixa; acidez potencial alta; soma de bases, CTC efetiva e CTC a pH 7,0, considerados bons; boa matéria orgânica; baixo teor de P; teor de P-rem muito baixo; alto teor de K; saturação de alumínio muito baixa; e média saturação de bases (ALVAREZ V. et al., 1999). A camada de 20-40 cm do solo apresentou acidez ativa do solo média; Ca trocável e Mg trocável com valores considerados bons; acidez trocável baixa; acidez potencial alta; soma de bases e CTC a pH 7,0 considerados bons; CTC efetiva média; boa matéria orgânica; teor de $\mathrm{P}$ e P-rem muito baixo; teor médio de K; saturação de alumínio muito baixa; e baixa saturação de bases (ALVAREZ V. et al., 1999).

A floresta restaurada com 40 anos apresenta um solo distrófico, provavelmente pelo histórico de ocupação do solo pela agricultura e plantio de eucalipto. Entretanto, a saturação de alumínio apresentou valores muito baixos (3,7\% e 9,9\%), e a densidade do solo da floresta se encontra dentro da faixa ideal para solos com textura argilosa. Isso demonstra que o solo vem-se recuperando e dando subsídio para a floresta alcançar estágios de maior equilíbrio e sustentabilidade.

\section{CONCLUSÕES}

A floresta restaurada por meio de plantio após 40 anos de sua implantação conseguiu alcançar parâmetros semelhantes ao das Florestas Estacionais Semideciduais, em estádio avançado de sucessão, da região de Viçosa, MG, em termos fitossociológicos do estrato arbustivo-arbóreo. Esse sucesso se deve também à chegada de propágulos dispersos por fragmentos florestais presentes no entorno da área, contribuindo, sobremaneira, com o aumento da diversidade florística e a atração à fauna.
A palmeira exótica Archontophoenix cunninghamiana está sendo prejudicial ao ecossistema em restauração por apresentar potencial de invasão. Portanto, recomenda-se o corte de seus indivíduos. Entretanto, outras espécies exóticas utilizadas no plantio não conseguiram se estabelecer e propagar e podem ter funcionado como catalisadoras de regeneração de espécies nativas.

\section{AGRADECIMENTOS}

À CAPES, pela bolsa de doutorado do primeiro autor; e ao CNPq, pela bolsa de Produtividade em Pesquisa do segundo autor e pela bolsa de mestrado do terceiro autor.

\section{REFERÊNCIAS}

ALVAREZ V., V. H. et al. Interpretação dos resultados das análises de solos. In: RIBEIRO, A. C.; GUIMARÃES, P. T. G.; ALVAREZ V., V. H. (Eds.). Recomendações para o uso de corretivos e fertilizantes em Minas Gerais: $5^{\mathrm{a}}$ aproximação. Viçosa, MG: CFSEMG, 1999. p.25-32.

\section{ANGIOSPERM PHYLOGENY GROUP III. APG} III. An update of the Angiosperm Phylogeny Group classification for the orders and families of flowering plants. Botanical Journal of the Linnean Society, v.161, n.2, p.105-121, 2009.

BERNACCI, L. C.; LEITÃO FILHO, H. F. Flora fanerogâmica da floresta da Fazenda São Vicente, Campinas, SP. Revista Brasileira de Botânica, v.19, n.2, p.149-164, 1996.

BRASIL. Resolução CONAMA n ${ }^{\circ} 392$, de 25 de junho de 2007. Dispõe sobre a definição de vegetação primária e secundária de regeneração de Mata Atlântica no estado de Minas Gerais. Diário Oficial da União. Brasília: Ministério do Meio Ambiente, 26 jun. 2007.

CARVALHO, F. A.; NASCIMENTO, M. T.; BRAGA, J. M. A. Composição e riqueza florística do componente arbóreo da Floresta Atlântica Submontana na região de Imbaú, Município de Silva Jardim, RJ. Acta Botanica Brasilica, v.20, n.3, p.727-740, 2006. 


\author{
CAstanho, G. G. Avaliação de dois \\ trechos de uma Floresta Estacional \\ Semidecidual restaurada por meio de \\ plantio, com 18 e 20 anos, no \\ Sudeste do Brasil. 2009. 111f. Dissertação \\ (Mestrado em Recursos Florestais) - Escola \\ Superior de Agricultura "Luiz de Queiroz", \\ Piracicaba. 2009.
}

CASTRO, P. S. et al. Interceptação da chuva por mata natural secundária na região de Viçosa MG. Revista Árvore, v.7, n.1, p.76-89, 1983.

DEAN, W. A ferro e fogo: a história e a devastação da Mata Atlântica brasileira. São Paulo: Companhia das Letras, 1996. 484 p.

DISLICH, R.; KISSER, N.; PIVELLO, V. R. A invasão de um fragmento florestal em São Paulo (SP) pela palmeira australiana Archontophoenix cunninghamiana $\mathrm{H}$. Wendl. e Drude. Revista Brasileira de Botânica, v.25, n.1, p.55-64, 2002.

DURIGAN, G. Estrutura e diversidade de comunidades florestais. In: MARTINS, S. V. (Ed.). Ecologia de florestas tropicais do Brasil. Viçosa, MG: Universidade Federal de Viçosa, 2009. 261p.

FERREIRA JÚNIOR, W. G. et al. Composição florística da vegetação arbórea de um trecho de floresta estacional semidecídua em viçosa, minas gerais, e espécies de maior ocorrência na região. Revista Árvore, v. 31, n.6, p.1121-1130, 2007.

GANDOLFI, S.; LEITÃO FILHO, H. F.; BEZERRA, C. L. F. Levantamento florístico e caráter sucessional das espécies arbustivo-arbóreas de uma floresta semidecídua no município de Guarulhos, SP. Revista Brasileira de Biololgia, v.55, n.4, p.753-767, 1995.

HASUI, E.; HÖFLING, E. Preferência alimentar das aves frugívoras de um fragmento de floresta estacional semidecídua secundária, São Paulo, Brasil. Iheringia, Série Zoologia, v.84, p.43-64, 1998.

HOBBS, R. J.; NORTON, D. A. Towards a conceptual framework for restoration ecology. Restoration Ecology, v.4, n.2, p.93-110, 1996.
LOPES, W. P. et al. Composição da flora arbórea de um trecho de Floresta Estacional no Jardim Botânico da Universidade Federal de Viçosa (face sudeste), Viçosa, Minas Gerais. Revista Árvore, v.26, n.3, p.339-347, 2002.

MAGURRAN, A. E. Ecological diversity and its measurement. London: Croom Hell, 1988. 179p.

MARANGON, L. C. Florística e fitossociologia de área de floresta estacional semidecidual visando dinâmica de espécies florestais arbóreas no município de Viçosa, MG. 1999. 135f. Tese (Doutorado em Ecologia e Recursos Naturais) - Universidade Federal de São Carlos, São Carlos, 1999.

MARANGON, L. C. et al. Estrutura fitossociológica e classificação sucessional do componente arbóreo de um fragmento de Floresta Estacional Semidecidual, no município de Viçosa, Minas Gerais. Cerne, v.13, n.2, p.208-221, 2007.

MARANGON, L. C.; SOARES, J. J.; SELICIANO, A. L. P. Florística arbórea da Mata da Pedreira no município de Viçosa, MG. Revista Árvore, v.27, n.2, p.207-215, 2003.

MARISCAL-FLORES, E. J. Potencial produtivo e alternativas de manejo sustentável de um fragmento de Mata Atlântica secundária, Município de Viçosa, Minas Gerais. Viçosa: Universidade Federal de Viçosa, 1993. 165f. Dissertação (Mestrado em Ciência Florestal) - Universidade Federal de Viçosa, Viçosa, MG, 1993.

MEIRA NETO, J. A. A.; MARTINS, F. R. Composição florística de uma Floresta EstacionalFsemidecidual Montana no município de Viçosa-MG. Revista Árvore, v.26, n.4, p.437-446, 2002.

MUELLER-DOMBOIS, D.; ELLENBERG, H. Aims and methods of vegetation ecology. New York, John Wiley \& Sons, 1974. 547p.

PAULA, A. et al. Sucessão ecológica da vegetação arbórea em uma Floresta Estacional Semidecidual, Viçosa, MG, Brasil. Acta

Botânica Brasílica, v.18, n.3, p.407-423, 2004.

PIELOU, E. C. Ecological diversity. New York: Jonhon Willey, 1975. 165p.

Revista Árvore, Viçosa-MG, v.36, n.5, p.869-878, 2012 
van der PIJL, L. Principles of dispersal in higher plants. 3.ed. Berlin/New York: SpringerVerlag, 1982. 214p.

PIÑA-RODRIGUES, F. C. M.; COSTA, L. G. S.; REIS, A. Estratégias de estabelecimento de espécies arbóreas e o manejo de florestas tropicais. In: CONGRESSO FLORESTAL BRASILEIRO, 6. 1990, Campos do Jordão. Anais... Campos do Jordão: SBS-SBEF, 1990. p.676-684.

PINTO SOBRINHO, F. A.; CHRISTO, A. G.; GUEDES-BRUNI, R. R. Composição florística e estrutura de um fragmento de Floresta Estacional Semidecidual Aluvial em Viçosa (MG). Floresta, v.39, n.4, p.793-805, 2009.

PINTO, S. I. C. et al. Estrutura do componente arbustivo-arbóreo de dois estádios sucessionais de floresta estacional semidecidual na Reserva Florestal Mata do Paraíso, Viçosa, MG, Brasil. Revista Árvore, v.31, n.5, p.823-833, 2007.

PIRANI, J. R.; CORTOPASSI-LAURINO, M. Flores e abelhas em São Paulo. 2.ed. São Paulo: Universidade de São Paulo, 1994.

SENRA, L. C. Composição florística e estrutura fitossociológica de um fragmento florestal da fazenda Rancho Fundo, na Zona da Mata - Viçosa, MG. 2000. 66f. Dissertação (Mestrado em Botânica) Universidade Federal de Viçosa, Viçosa, MG, 2000.

SERVIÇO FLORESTAL BRASILEIRO. Florestas do Brasil em resumo. Brasília: Ministério do Meio Ambiente, 2009. 121p.

SHEPHERD, G. J. Fitopac 2.1 - Campinas, Departamento de Botânica, Universidade Estadual de Campinas, 2010.

SILVA, A. F.; FONTES, N. R. L.; LEITÃO FILHO, H. F. Composição florística e estrutura horizontal do estrato arbóreo de um trecho da Mata da Biologia da Universidade Federal de Viçosa. Revista Árvore, v.24, n.4, p.397-406, 2000.
SILVA, A. F. et al. Composição florística e grupos ecológicos das espécies de um trecho de floresta semidecídua submontana da Fazenda São Geraldo, Viçosa-MG. Revista Árvore, v.27, n.3, p.311-319, 2003.

SILVA JÚNIOR, W. M. et al. Regeneração natural de espécies arbustivo-arbóreas em dois trechos de uma Floresta Estacional Semidecidual, Viçosa, MG. Scientia Forestalis, n.66, p.169-179, 2004.

SOUZA, F. M.; BATISTA, J. L. F. Restoration of seasonal semideciduous forests in Brazil: influence of age and restoration design on forest structure. Forest Ecology and Management, v.191, p.185-200, 2004.

STATSOFT, INC. Statistica - Data analysis software system. Version 7.0.61.0. Tulsa: 2004.

VELOSO, H. P.; RANGEL-FILHO, A. L. R.; LIMA, J. C. A. Classificação da vegetação brasileira, adaptada a um sistema universal. Rio de Janeiro: Instituto Brasileiro de Geografia e Estatística, 1991. 124p.

VELOSO, H. P. Sistema fitogeográfico. In: INSTITUTO BRASILEIRO DE GEOGRAFIA E ESTAtisticA, (Ed.). Manual técnico da vegetação brasileira. Brasília: 1992. p.8-38. (Série Manuais Técnicos em Geociências, v.1)

VOLPATO, M. M. L. Regeneração natural em uma floresta secundária no domínio de Mata Atlântica: uma análise fitossociológica. 1994. 123 f. Dissertação (Mestrado em Ciência Florestal) - Universidade Federal de Viçosa, Viçosa, MG, 1994.

WATERHOUSE, J. T.; QUINN, C. J. Growth patterns in the stem of the palm Archontophoenix cunninghamiana. Botanical Journal of the Linnean Society, v.77, n.1, p.73-93, 1978. 